\title{
A VOLT SCALE FOR A WATTS-PER-CANDLE METER.
}

\author{
By Herbert E. Ives.
}

Volt scales, indicating the voltage to give a desired candlepower, have been used on photometers in many incandescentlamp factories. They are better adapted to the requirements of the lamp trade than are candlepower reading scales, because the demand is not for a large range of candlepowers at one voltage, but for few candlepowers with considerable latitude in voltages. Recently, the introduction of the graphitized and new metallic filament lamps has been marked by a new and more rational classification, namely, by watts per candle and total watts. To the writer's knowledge, however, there has not been developed a method of reading directly from the photometer the voltage to give the desired watts per candle and the watts corresponding to that voltage. Candlepower, current, and voltage readings are made, none of which is necessarily the final value adopted, and sorting is done by rough calculation, aided by limit tables and by experience. It would obviously be advantageous to obtain the voltage giving the correct watts per candle by direct reading, and, if possible, the corresponding watts or candlepower at the same time. The sorting of lamps would then be more quickly and probably more accurately done than by an indirect method. The efficiency-meter volt scale here described accomplishes this object.

A watts-per-candle or efficiency meter, designed by Hyde and Brooks, is part of the photometric equipment of the Bureau of Standards. ${ }^{1}$ It consists essentially of a wattmeter with a variable 
pressure-circuit resistance, so arranged that as the photometer screen moves the wattmeter reads watts per candle. This instrument lends itself to the operation of finding the volts for a given efficiency by the method of trial and error. Where the number of lamps is small and time not too short, it affords a convenient and exact means of finding the voltage in question. In the extensive testing done by the Bureau for various Government departments, under the Bureau's specifications, carbon lamps are run on life test at a uniform efficiency of 3.1 watts per mean horizontal candle. This necessitates determining for each lamp the voltage which gives this efficiency. Finding the voltage by trial, with the efficiency meter, proved too long an operation to be practicable with a large number of lamps, and a shorter procedure was sought.

Experiment showed it possible to calculate with considerable accuracy, from the watts per candle at rated voltage (an initial run at rated voltage is part of the regular test), the voltage to give 3.I watts per candle, by use of the relation $\left(\frac{V_{2}}{V_{1}}\right)^{k}=\frac{w p c_{1}}{w p c_{2}}$ where for the range from 3.6 to 3.1 wpc., for treated carbon filaments, $k$ has the value $3 \cdot 5$. The results of such a calculation may be used in the form of percentage tables, or the actual volt values may be calculated for each rated voltage met with, and then tabulated. From such a table, for instance, it can be read that a I IO-volt lamp operating at 3.5 watts per candle must be raised to I 3.7 volts to operate at $3 . \mathrm{I} \mathrm{wpc}$. Tables so calculated greatly reduce the work of finding the 3.1 voltage. It seemed desirable, however, to further reduce the number of operations, and this was accomplished by placing a scale in the efficiency meter which indicates at once the data of the tables.

This scale is a volt scale, similar in idea to the volt scales used in assigning lamps to the 16 or 32 candlepower voltage, but differing in that it indicates the voltage that will give a certain watts per candle. With a photometer operated at one voltagesay I Io-it is only necessary to place in the efficiency meter a new scale which shall read I IO at the 3.I point (assuming 3.I to be the watts per candle desired), III at 3.2I, II 2 at 3.315, etc., in accordance with the voltage-watts-per-candle relation. The 
position of the photometer screen for intensity match then gives on the new scale the 3.I voltage.

In the Bureau of Standards work a complication arose from the fact that lamps must be measured at rated voltage, and the number of rated voltages is so large that separate scales for each can not be conveniently placed within the instrument. Resort was had to an optical device to accomplish the same purpose. A series of volt scales for each voltage from 80 to I 30 were drawn, one above another, on a narrow strip of paper. Their 3.I points being in a straight line, the volt marks when joined formed smooth curves, and the resultant complete scale consisted of a series of converging volt lines crossed at right angles by curved lines numbered to indicate the corresponding rated voltages. This scale was fastened on a small cylinder mounted to permit of rotation about a horizontal axis above the efficiency meter scale. On top of the latter instrument was fastened a silvered glass mirror from whose lower surface the silver had been removed up to a curved line, whose curvature was approximately that of the instrument scale. This mirror, so placed that no parallax exists between the needle and the image of the outside scale, permits of reading the volts from any volt line which has been turned to a fixed pointer, by merely placing the eye in position to see the volt line at the edge of the silver mirror, and observing the needle past the edge. This operation is no more difficult than the usual sighting of a needle over its image, and as quick. Since there is no parallax, special pains need not be taken to have the eye exactly centered laterally; in fact, both eyes may be used. The instrument in this form has been used with complete success in the Bureau's testing of carbon lamps.

A possible application of the volt scale efficiency meter is in the rating and sorting of lamps according to watts per candle, the quantity now recognized as of most importance. By having factory photometers operated at definite voltages, as is done with present volt-scale photometers, it is at once evident that voltscale efficiency meters would indicate at one reading the voltage at which lamps should be rated. A further requirement must be met before the lamp is completely rated, namely, the candlepower or watts at the voltage indicated should be given. This can 
readily be done by an extension of the volt-scale idea. It is only necessary, if we desire candlepower indication, to have scales on the photometer bench giving the candlepowers at various voltages corresponding to candlepowers at the voltage used. For instance, the I6-candlepower point for the i Io-volt scale would be the I 9.5-candlepower point on the II 4-volt scale. These scales, whose similarly numbered points may be joined by continuous lines, may be conveniently mounted on a cylinder, as is done at present with different candlepower scales where sector disks are used. When a voltage is indicated by the efficiency meter scale, the candlepower scale should be turned to the point corresponding to that voltage-a line on the cylinder, or a division on the turning mechanism. The candlepower at rated voltage is then shown by the pointer attached to the photometer screen.

If watts are desired, a similar watt scale may be made whose readings are the candlepowers in the above scale multiplied by the common watts per candle. In this case the watt reading would of course be subject to the errors of photometric setting. An alternative form of watt scale could be made by multiplying the actual efficiency reading by the candlepower reading, by the use of scales, each corresponding to an efficiency, mounted upon a cylinder as described above. In this way the candlepower reading is eliminated, and watts at the photometer voltage may be read independent of errors of candlepower estimation. Instead of actual watts, watts at the voltage corresponding to the efficiency meter indication may be plotted in a manner similar to that described for candlepowers.

It is therefore possible by combining a volt scale on a wattsper-candle meter with proper scales on the photometer, to read from one photometer setting-

I. Voltage to give a certain efficiency.

2. Candlepower or watts at that voltage.

In short, the quantities now desired in rating incandescent lamps are obtained at one operation.

It is of practical interest to know how accurately lamps may be placed at a desired watts per candle by the use of a volt scale efficiency meter. It is obvious that this depends upon the uniformity with which individual lamps conform to the voltage- 
watts-per-candle relation used in plotting the scale. Experiment with about 2000 lamps of several different makes has shown that those of any one make can be placed regularly within a range from 3.05 to $3.15 \mathrm{wpc}$. from readings made in the neighborhood of $3.50 \mathrm{wpc}$. With different makes the amount of "treatment" of the filament varies, calling for a different voltage exponent. This change of exponent has been found to be accounted for by the changed voltage-candlepower exponent; that is, if the exponent in the equation $\left(\frac{V_{2}}{V_{1}}\right)^{k}=\frac{c p_{2}}{c p_{1}}$ is 5.7 instead of 5.5 , the exponent in the equation $\left(\frac{V_{2}}{V_{1}}\right)^{k}=\frac{w p c_{1}}{w p c_{2}}$ is 3.7 instead of $3.5{ }^{2}$ In other words, any shortcoming in the efficiency meter volt scale plan is only such as would be met with in using a volt scale for candlepower work with the same lamps. In any one factory where the product is reasonably uniform, a wattsper-candle volt scale should be quite as practical as the present volt-scale photometer.

WASHIngton, February 27, I909.

${ }^{2}$ See article by F. E. Cady, Illuminating Engineering Society Convention, October, 1908. 